Fourth International Conference on Sustainable Construction Materials and Technologies

http://www.claisse.info/Proceedings.htm

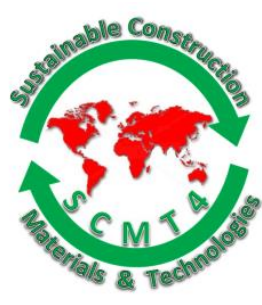

SCMT4

Las Vegas, USA, August 7-11, 2016

\title{
Low-Carbon Eco-Friendly Concrete Structure Constructed by Microwave Heat Curing Technology
}

\author{
Tae-hoon Koh ${ }^{1 a}$, Seon-keun Hwang ${ }^{1 b}$, Jung-hoon Yoo ${ }^{1 c}$, and Han-ju Yoo ${ }^{1 d}$ \\ ${ }^{1}$ Korea Railroad Research Institute, 16105, \#176 Cheoldo bakmulkwan-ro, Uiwang-si, Gyeonggi-do, \\ South Korea, ${ }^{1 a}$ Email: <thkoh@krri.re.kr>, ${ }^{1 b}$ Email: <skhwang@krri.re.kr>, \\ ${ }^{1 c}$ Email: <hoon0323@gmail.com>, ${ }^{1 d}$ Email: $\langle k c d o c 2 @ k r r i . r e . k r>$.
}

\begin{abstract}
Low-carbon eco-friendly concrete structure was constructed by microwave heat curing technology, which have been newly developed for railway infrastructure in Korea. In this study, typical industrial byproducts (steel slag and fly ash) were used as ingredients of the low-carbon eco-friendly concrete. In other words, Portland cement was partially replaced by GGBF (Ground Granulated Blast Furnace) slag and fly ash, and rapid cooling EAF (Electric Arc Furnace) oxidizing slag was used as an alternative to fine aggregates. The curing of precast concrete structure is one of main production processes which represents about $70 \%$ of its total manufacturing period, and at least around $10 \%$ of its manufacturing cost. The conventional steam curing inevitably depends on fossil fuel consumption, causes rust on the steel form then significant reduction in its lifespan, and always makes the precast plant damp. With such a background, microwave heat curing technology has been newly developed in Korea, which can produce the precast concrete structure environmentally and economically. From the field test for precast concrete culvert, it was found that this technology is able to complete the whole curing process only by electric power without fossil fuel, and provides the clean precast plant. Besides, microwave heat curing technology substantially reduced the curing cost by around 50\% without loss of concrete quality (strength) comparing with conventional steam curing. This newly developed sustainable low-carbon eco-friendly concrete significantly reduces the usage of cement and natural fine aggregates in its manufacturing, and then contributes to reduce the construction cost for railway concrete infrastructure.
\end{abstract}

\section{INTRODUCTION}

Precast concrete has been used so far for reasons of high productivity and constructability. Precast concrete in Europe has been developed for small to large buildings as well as for structural member and even finishing materials.

In North America, though it was developed late, a number of studies have been conducted in the area of building and civil structure jointly by many organizations including NPCA and PCI in USA. Japan has applied precast concrete to the buildings and civil structure the most in Asia. The efforts to develop the precast concrete technologies have been made jointly or in collaboration with many member companies of JPCSMA (Japan Prefabricated Construction Suppliers and Manufacturers Association) which plays the leading role in technology development, policy recommendation, standard \& system development and 
systematic training of engineers. Therefore in Europe, North America and Japan, cast-in-place concrete has been replaced with precast concrete that minimizes the workforce at many construction sites.

However, the conventional precast concrete technology has critical issues in manufacturing: the conventional steam curing inevitably depends on fossil fuel consumption, causes rust on the steel form then significant reduction in its lifespan, and always makes the precast plant damp.

On the other hand, carbon dioxide $\left(\mathrm{CO}_{2}\right)$ emissions from the cement production have been recently one of the main social issues, and natural aggregates for concrete has been insufficient to supply the demand due to the growth of concrete industry. Recently the important social impacts of recycled materials as concrete ingredients are widely recognized.

From this point of view, in this study, low-carbon eco-friendly PC culvert, which was developed to reduce the usage of cement and natural resources (fine aggregate) as main ingredients of the concrete, was environmentally and economically-friendly manufactured by microwave heat curing technology which has been newly developed in Korea..

\section{BACKGROUND}

Conventional steam curing. Conventional steam curing is generally applied in most of precast concrete plants to obtain early strength within a short time. Among the problems with steam curing are excessive energy consumption, early replacement of corroded steel form and air contamination by using fossil fuel.

Developed microwave heat curing. As part of the effort to cope with such problems, microwave heat curing technology is able to complete the whole curing process only by electric power without fossil fuel, and provide the clean precast plant. Microwave heat curing system is applied to steel form for the precast concrete structure as shown in figure 1. In this system, microwave generated from magnetron is irregularly reflected inside the cavity and rapidly heats the microwave-exothermic body so that the heat is transferred into the concrete through the steel form to accelerate the concrete hydration [Koh, 2014].

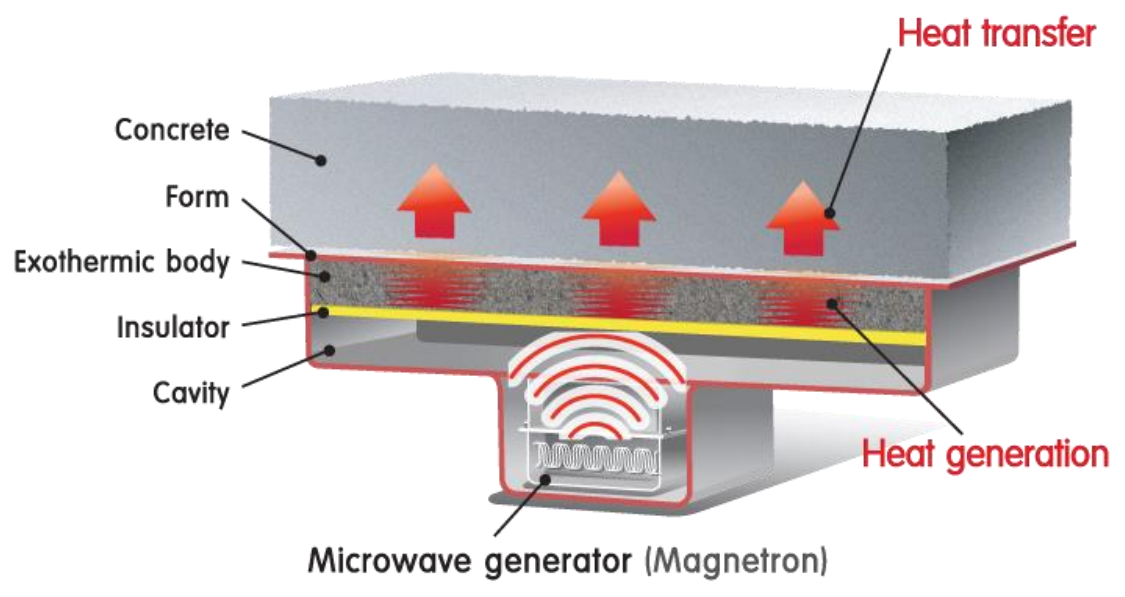

Figure 1. Microwave Heat Curing System [Koh, 2014] 


\section{EXPERIMENTAL PROGRAM}

Low-carbon Eco-friendly Mixing Design. For the manufacture of low-carbon eco-friendly PC culvers, Portland cement was partially replaced by GGBF (Ground Granulated Blast Furnace) slag and fly ash, and rapid cooling EAF (Electric Arc Furnace) oxidizing slag was used as an alternative to fine aggregates. In this study, low-carbon eco-friendly concrete mixing was done based on the design strength of $35 \mathrm{MPa}$ and slump $175 \mathrm{~mm}$.

Curing Cycle. Microwave heat curing was operated in the same way as conventional steam curing cycle as shown in Figure 2. In this study, microwave heat curing cycle consists of Initial delay (Preset time) - Heating (Ramp time) - Treatment (Holding time) - Cooling (Soak time) stages (Gurley, 2011).

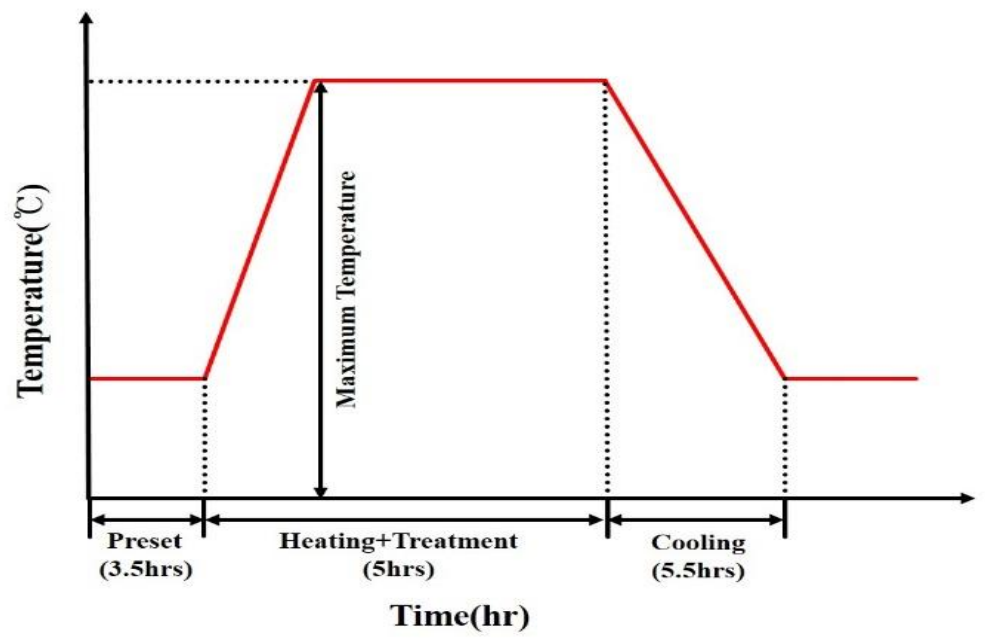

Figure 2. Curing Cycle

Table 1 shows the cycles for tested steam curing and microwave heat curing respectively. A total 14 hours curing histories have been applied to both curing systems which consists of preset (3.5hrs) - heating \& treatment (5hrs) - cooling (5.5hrs) stages. The effect of microwave heat curing was evaluated for the compressive strength of initially cured concrete, which was also compared with conventional steam curing condition.

Table 1. Cycles and Temperatures for tested Steam Curing and Microwave Heat Curing

\begin{tabular}{|c|c|c|c|c|c|}
\hline No. & Curing Method & $\begin{array}{c}\text { Preset } \\
(\mathrm{hrs})\end{array}$ & $\begin{array}{c}\text { Heating \& Treatment } \\
(\mathrm{hrs})\end{array}$ & $\begin{array}{c}\text { Cooling } \\
(\mathrm{hrs})\end{array}$ & Max. Temp. $\left({ }^{\circ} \mathrm{C}\right)$ \\
\hline 1 & Microwave Heat Curing & 3.5 & 5 & 5.5 & 65 \\
\hline 2 & Steam Curing & 3.5 & 5 & 5.5 & 55 \\
\hline
\end{tabular}

Steel form for PC culvert (2.45m high, $4.9 \mathrm{~m}$ long, $1.0 \mathrm{~m}$ wide) was prepared for the evaluation of the fundamental properties of low-carbon eco-friendly concrete by microwave heat curing and steam curing (see Figure 3). For the preparation of microwave heat cured PC culvert, microwave heat curing systems were attached to three sides of the form at certain intervals, and he surface of the form was finished with insulation to preserve the heat developed from the microwave heating surface of the form (see Figure 4). 


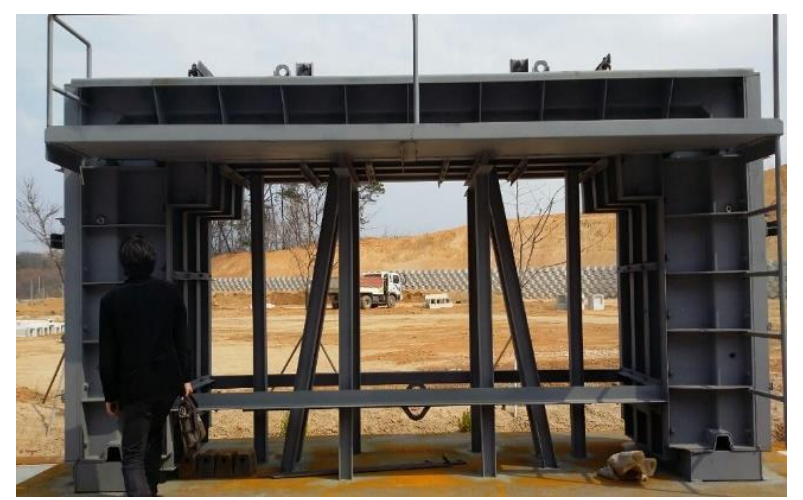

Figure 3. (a) Steal Form for Steam Curing

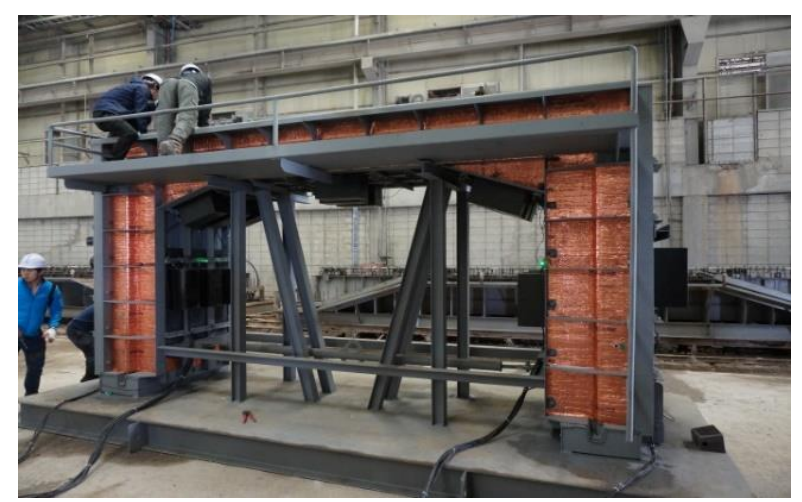

(b) Steal Form for Microwave Heat Curing

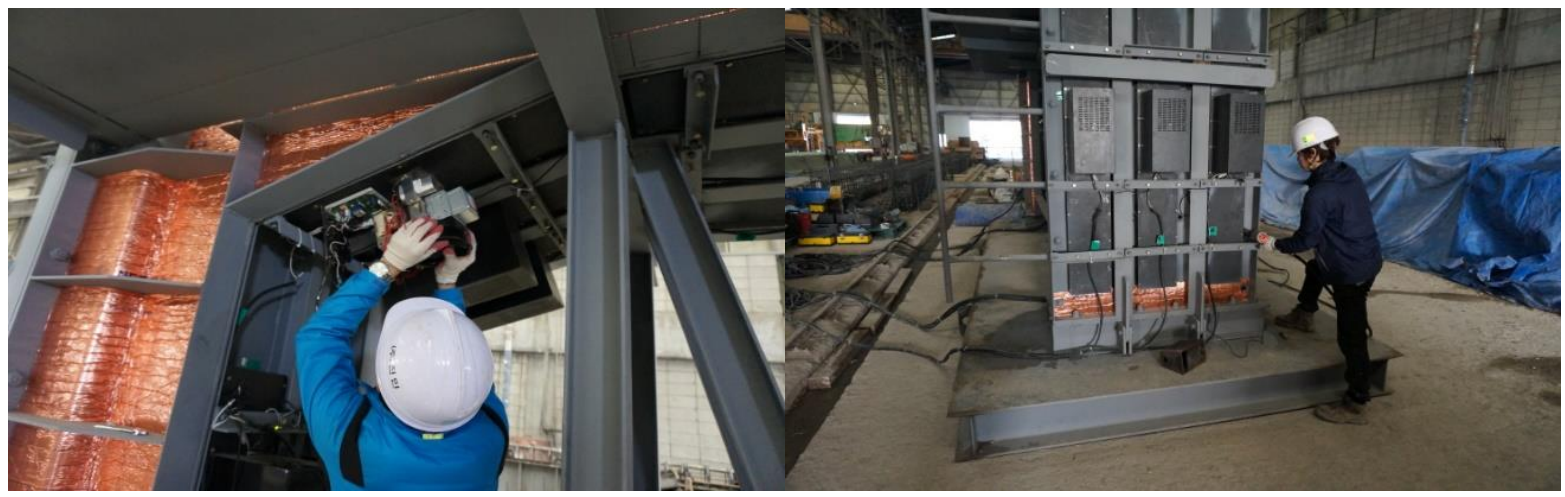

Figure 4. Installation of Microwave Heat Curing Systems to the Form

\section{RESULTS AND ANALYSIS}

Release of PC Structures. Figure 5 shows the microwave heat cured and steam cured PC culverts released after 14 hours. The microwave heat cured PC culvert (Figure 5 (a)) was produced only by steal form with microwave heating systems without any help of fossil fuel and curing facilities.
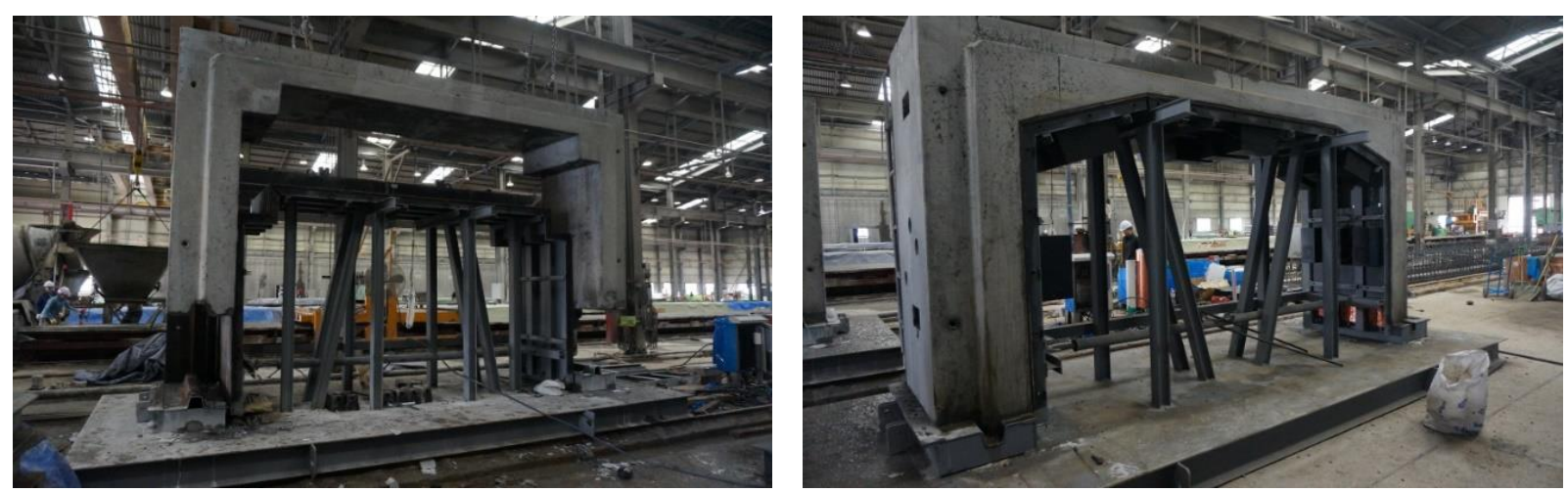

Figure 5. (a) Steam cured PC Culvert (b) Microwave Heat cured PC Culvert 


\section{Compressive Strength}

Compressive strength was measured after microwave heat curing and steam curing, core samples were taken from the each initially cured PC culvert surface. Compressive strength test was conducted in accordance with KS F 2422 and KS F 2405.

Compressive strength was described on Table 2 depending on curing method. As a result, microwave heat cured concrete showed a similar strength level with steam curing condition. It is found that regardless of curing conditions, low-carbon eco-friendly concrete sufficiently satisfies the initial and designed strength with low $\mathrm{CO}_{2}$ emission.

Table 2. Compressive Strength

\begin{tabular}{|c|c|c|c|c|c|}
\hline & \multirow{2}{*}{$\begin{array}{c}\text { Max. } \\
\text { Temperature } \\
\end{array}$} & \multicolumn{4}{|c|}{ Compressive Strength (MPa) } \\
\cline { 3 - 6 } & ${ }^{\circ}$ ) & 1 day & 1 month & 3 months & 6months \\
\hline Microwave Heat Curing & 65 & 23.1 & 66.8 & 63.6 & 70.1 \\
\hline Steam Curing & 55 & 21.1 & 61.2 & 62.5 & 67.8 \\
\hline
\end{tabular}

* Max. Temperature is measured at the surface of the form where the concrete faces

Chemical Corrosion Resistance. The durability tests were conducted with 1, 3 and 6 monthly aged cored samples in accordance with ASTM C267. As one of the durability performances, chemical corrosion resistance test was performed to estimate the effect of its exposure to severe environmental conditions. As shown is Table 3, variations of compressive strength at $10 \%$ $\mathrm{Na}_{2} \mathrm{SO}_{4}$ immersion were less than $10 \%$, which is due to the GGBF slag with latent hydraulic properties.

\section{Table 3. Compressive strength rate of change}

\begin{tabular}{|c|c|c|c|c|c|}
\hline & \multicolumn{2}{|c|}{ Microwave Heat Curing } & \multicolumn{2}{|c|}{ Steam Curing } \\
\hline & & $\begin{array}{l}\text { Compressive } \\
\text { Strength } \\
\text { (MPa) }\end{array}$ & $\begin{array}{c}\text { Rate of change } \\
(\%)\end{array}$ & $\begin{array}{l}\text { Compressive } \\
\text { Strength } \\
\text { (MPa) }\end{array}$ & $\begin{array}{l}\text { Rate of change } \\
(\%)\end{array}$ \\
\hline \multirow[b]{2}{*}{1 month } & Before immersion & 60.2 & - & 56.4 & - \\
\hline & $\begin{array}{c}10 \% \mathrm{Na}_{2} \mathrm{SO}_{4} \\
\text { immersion }\end{array}$ & 59.5 & -1.2 & 55.5 & -1.6 \\
\hline \multirow[b]{2}{*}{3 months } & Before immersion & 63.6 & - & 62.5 & - \\
\hline & $\begin{array}{c}10 \% \mathrm{Na}_{2} \mathrm{SO}_{4} \\
\text { immersion }\end{array}$ & 61.3 & -3.6 & 59.7 & -4.5 \\
\hline \multirow[b]{2}{*}{6 months } & Before immersion & 64.4 & - & 65.1 & - \\
\hline & $\begin{array}{c}10 \% \mathrm{Na}_{2} \mathrm{SO}_{4} \\
\text { immersion }\end{array}$ & 61.3 & -4.8 & 59.8 & -8.1 \\
\hline
\end{tabular}

Salt Resistance. The chloride ion penetration test was performed to estimate salt resistance of tested concrete in accordance with KS F 2711. As shown in Table 4. Chloride ion penetrability of each aged sample represents "Very Low" rating based on Table 5, which is due to dense structure of low-carbon eco-friendly concrete developed with GGBF slag-blended binder and EAF oxidizing slag aggregate (Chen, 2006). 
Table 4. Chloride ion penetrability

\begin{tabular}{|c|c|c|c|}
\hline \multirow{2}{*}{} & \multicolumn{3}{|c|}{ Chloride ion penetration resistance (coulombs) } \\
\cline { 2 - 4 } & 1 month & 3 months & 6months \\
\hline Microwave Heat Curing & 361 & 217 & 214 \\
\hline Steam Curing & 399 & 189 & 171 \\
\hline
\end{tabular}

Table 5. Chloride ion penetrability based on charge passed

\begin{tabular}{|c|c|c|c|c|c|}
\hline $\begin{array}{c}\text { Total passed } \\
\text { charge (coulombs) }\end{array}$ & $>4,000$ & $2,000 \sim 4,000$ & $1,000 \sim 2,000$ & $100 \sim 1,000$ & $<100$ \\
\hline $\begin{array}{c}\text { Chloride ion } \\
\text { penetrability }\end{array}$ & High & Moderate & Low & Very low & Negligible \\
\hline
\end{tabular}

Freezing and Thawing Resistance. Table 6 and figure 6 show freezing and thawing resistance test results based on the relative dynamic modulus of elasticity in accordance with KS F 2456. Microwave heat cured concrete showed similar level of freezing and thawing resistance with steam curing condition. GGBF slag and fly ash-blended binder used for tested concrete led to high level of freezing and thawing resistance.

Table 6. Relative dynamic modulus of elasticity (\%)

\begin{tabular}{|c|c|c|}
\hline & Microwave Heat Curing & Steam Curing \\
\hline 1month & 89.3 & 89.1 \\
\hline 3months & 90.2 & 89.9 \\
\hline 6months & 91.7 & 92.0 \\
\hline
\end{tabular}

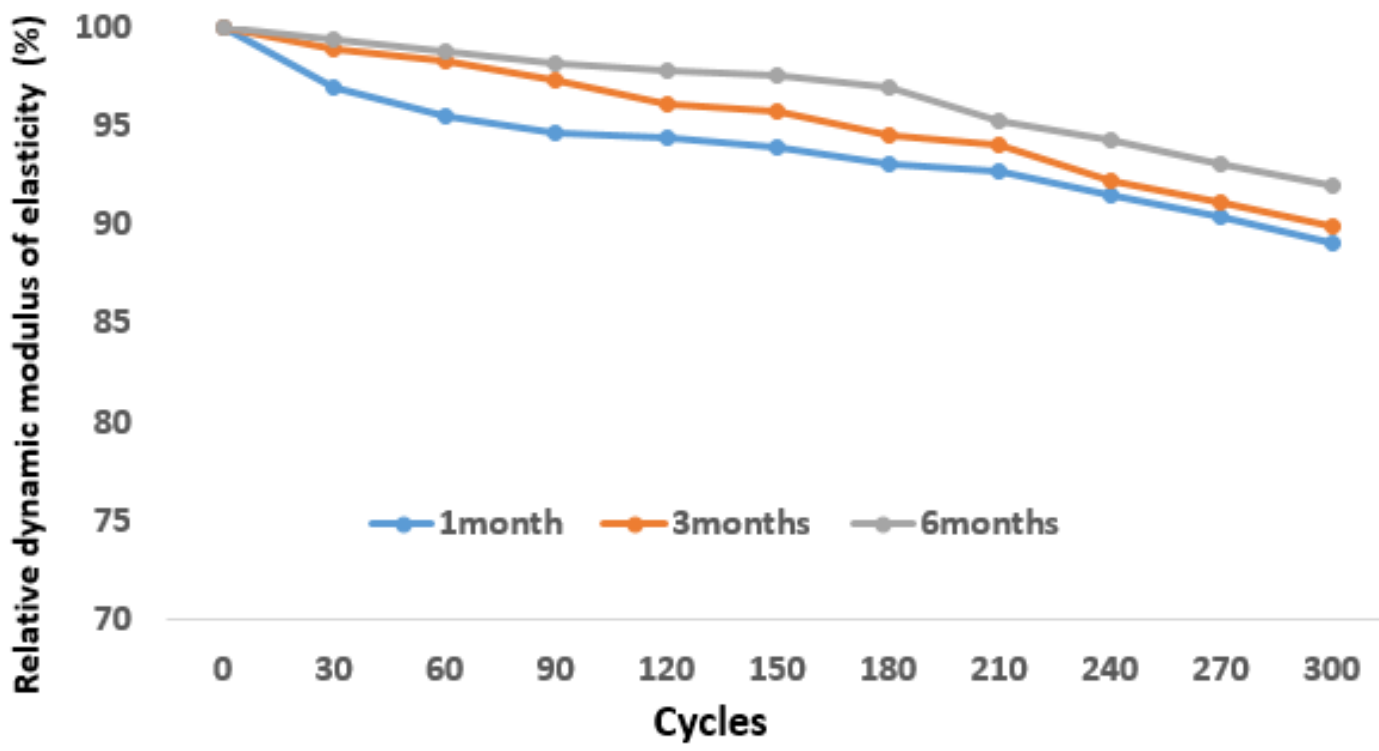

Figure 6. (a) Freezing and thawing resistance - Microwave heat curing 


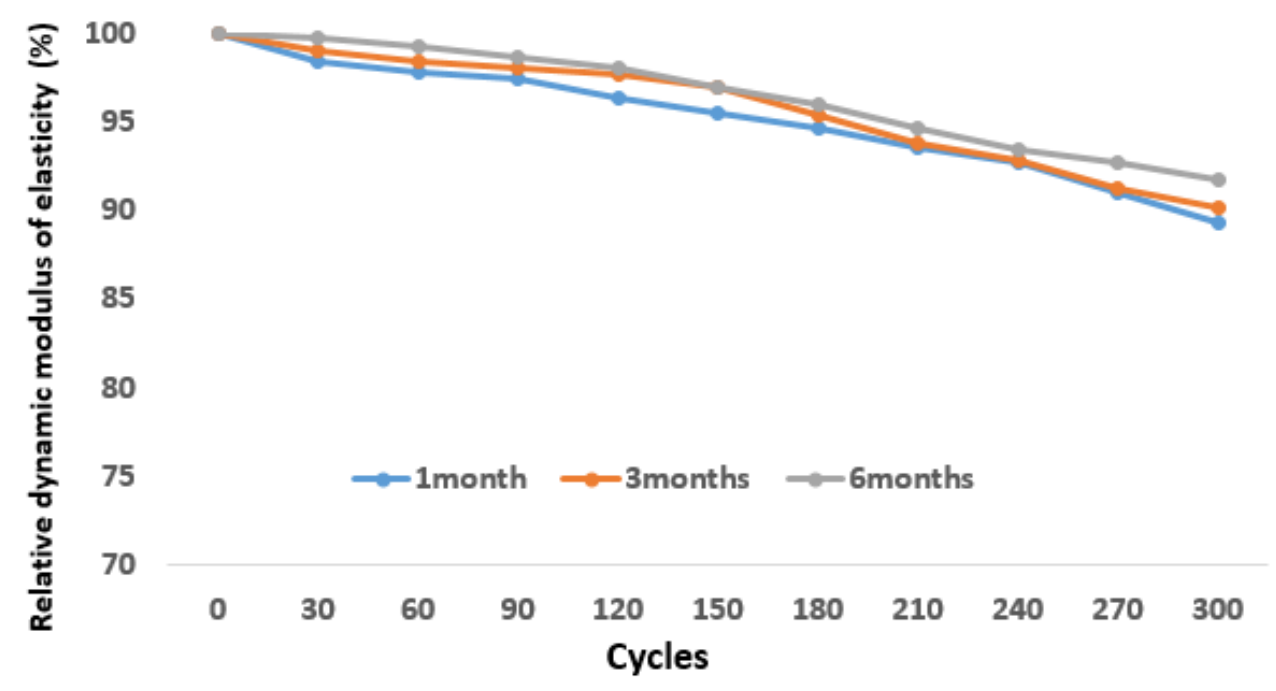

Figure 6. (b) Freezing and thawing resistance - Steam curing

\section{Curing Cost}

For the simple estimation of curing cost in aspect of energy, whole power consumption was monitored during microwave heat curing for manufacturing PC structure in this study. As shown in Table 7, microwave heat curing technology can reduce the curing cost by around $70 \%$ comparing with conventional steam curing method. Therefore, the microwave heat curing system can be an economical alternative to the conventional steam curing method for PC structures.

Table 7. Energy cost for curing

\begin{tabular}{|l|c|c|}
\hline \multirow{2}{*}{} & \multicolumn{2}{|c|}{ Energy Cost for Curing (\$/ton) } \\
\cline { 2 - 3 } & M/W Heat Curing & Steam Curing \\
\hline PC culvert & 1.72 & 5.74 \\
\hline
\end{tabular}

\section{CONCLUSION}

Steam curing is general curing method in PC plant to obtain early required strength within a short curing time so as to increase concrete productivity. However steam curing method results in cost increase due to use of fossil fuels, expensive curing facilities, excessive energy consumption, corrosion of steel form by steam, poor working environment by steam and complex process. As part of the effort to cope with such problems, newly developed microwave heat curing technology was evaluated in this study.

- Microwave heat cured concrete has similar levels of short and long- term strength and durability with steam curing condition.

- Significant reduction in production expense by microwave heat curing technology is expected due to lower curing cost than conventional steam curing method.

Regardless of curing conditions, low-carbon eco-friendly concrete developed in this study showed good levels of short and long- term strength and durability with a help of alternative binders and aggregate

- Steel slag is suitable alternative concrete ingredients to cement and natural resources for concrete infrastructure applications.

- Low-carbon eco-friendly concrete can contribute to reduce carbon dioxide $\left(\mathrm{CO}_{2}\right)$ emissions in concrete infrastructure. 


\section{REFERENCES}

ASTM, West Conshohocken. (2012). Standard Test Method for Resistance of Mortars, Grouts, and Monolithic Surfacings and Polymer Concrete, ASTM C 267

Chen, W. (2006). "Hydration of slag cement: Theory, modeling and application." Ph.D. thesis, University of Twente, Enschede, Netherlands, 29-32

Gurley, E. (2011). "To cure or Not to cure?" http://precast.org/2011/07/to-cure-or-not-to-cure/>

Koh, T. (2014). "Fast curing technology for Concrete." 2014 International Seminar on Innovations for Future Transportation, Special Session.

Korean Agency for Technology and Standards. (2007). Method of obtaining and testing drilled cores and sewed beams of concrete KS F 2422.

Korean Agency for Technology and Standards. (2010). Standard test method for compressive strength of concrete KS F 2405.

Korean Agency for Technology and Standards. (2013). Standard test method for resistance of concrete to rapid freezing and thawing KS F 2456

Korean Agency for Technology and Standards. (2002). Testing method for electrical indication of concrete's ability to resist chloride ion penetration KS F 2711 